\title{
Pharmacokinetic characteristics of telaprevir in healthy Korean male subjects and comparisons with Japanese
}

This article was published in the following Dove Press journal:

Drug Design, Development and Therapy

\author{
Yewon Choi' \\ Seonghae Yoon' \\ Kyoko Matsumoto 2 \\ Yoshiyasu Ohta ${ }^{3}$ \\ SeungHwan Lee' \\ Kyung-Sang $\mathrm{Yu}^{\prime}$ \\ In-Jin Jang' \\ 'Department of Clinical Pharmacology \\ and Therapeutics, Seoul National \\ University College of Medicine \\ and Hospital, Seoul, Republic of \\ Korea; ${ }^{2}$ lkuyaku Integrated Value \\ Development Division, Mitsubishi \\ Tanabe Pharma Corporation, Osaka, \\ Japan; ${ }^{3}$ Sohyaku Innovative Research \\ Division, Mitsubishi Tanabe Pharma \\ Corporation, Tokyo, Japan
}

Introduction: Telaprevir, a reversible selective inhibitor of viral protease and a potential blocker of viral replication, is indicated for the treatment of hepatitis $\mathrm{C}$ virus genotype 1 infection. In this study, the pharmacokinetic profile, safety, and tolerability of telaprevir and the effect of food on telaprevir exposure were evaluated in healthy Korean subjects, and compared with data from a previous study in Japanese male subjects.

Methods: The single ascending dose study was conducted in 3 dose-based groups $(500,750$, and $1,250 \mathrm{mg}$, six subjects each) in a fasted state. In the multiple dose study, eight subjects in the fed state received $750 \mathrm{mg}$ of telaprevir once on Day 1 and every 8 hours from Day 2 until the morning of Day 6. Serial blood samples for pharmacokinetic analysis were collected for up to 24 hours in the single ascending dose study and for 6 days in the multiple dose study. Individual pharmacokinetic parameters were calculated using a non-compartmental analysis method. Safety and tolerability profiles were evaluated throughout the study.

Results: Following multiple administrations of telaprevir, maximum plasma concentrations $\left(\mathrm{C}_{\max }\right)$, area under the concentration-time curve $\left(\mathrm{AUC}_{0-8}\right)$, and $\mathrm{C}_{\text {trough }}$ (concentration at $8 \mathrm{~h}$ after drug administration) increased by $\sim 2.41$-fold. Compared to fasted state values, mean $\mathrm{C}_{\max }$ and $\mathrm{AUC}_{0-24}$ increased by 4.92- and 4.81-fold, respectively, after food intake. $\mathrm{The}_{\text {max }}$ and $\mathrm{AUC}_{\text {inf }}$ of Korean subjects were $26 \%-34 \%$ higher than those of Japanese subjects; however, these differences were not clinically significant. All observed adverse events were mild and there was no discontinuation due to AEs

Conclusion: In conclusion, the telaprevir's pharmacokinetic characteristics were similar in Korean and Japanese subjects. Telaprevir was well tolerated in a single dose of up to $1,250 \mathrm{mg}$ and in multiple doses of $750 \mathrm{mg}$.

Keywords: antiviral agents, hepatitis $\mathrm{C}$ virus, NS3/4A protease, ethnicity, pharmacokinetic profile

\section{Introduction}

Hepatitis $\mathrm{C}$ virus (HCV) is one of the major causes of liver disease and may lead to liver cirrhosis, hepatocellular cancer, liver failure, and even death. ${ }^{1}$ While HCV is prevalent worldwide, the most affected regions are North Africa, Central Asia, and East Asia. ${ }^{2}$ Among the seven recognized genotypes (1-7) of HCV strains, HCV genotype 1 is considered responsible for the majority of $\mathrm{HCV}$ cases in East Asia.

Although a large proportion of the HCV infection cases in Korea are caused by HCV genotype 1, only a few treatment options are currently available. Telaprevir is a reversible, selective inhibitor of the $\mathrm{HCV} \mathrm{NS3/4A} \mathrm{protease,} \mathrm{which} \mathrm{results} \mathrm{in} \mathrm{inhibition}$ of viral replication. ${ }^{3}$ Orally administered telaprevir is absorbed in the small intestine, 
metabolized extensively in the liver, and eliminated in the feces. ${ }^{4,5}$ Approved in 2011 in the USA and Japan, telaprevir is indicated, in combination with peg-interferon alpha and ribavirin, for the treatment of HCV genotype 1 infection. ${ }^{6}$ The Korean Ministry of Food and Drug Safety requires supporting data regarding telaprevir pharmacokinetics (PK), pharmacodynamics, safety, and dosing regimens in order to extrapolate foreign clinical data to the Korean population. The Ministry of Food and Drug Safety also accepts a PK study if a drug is less likely to be sensitive to ethnic factors. ${ }^{7}$ According to previous studies, telaprevir has a flat effect-concentration curve for efficacy and safety and a wide therapeutic dose range, undergoes metabolism via cytochrome P450 (CYP)3A4 and other multiple pathways including non-CYP-mediated metabolism, ${ }^{5}$ and has little potential for inappropriate use. ${ }^{8,9}$ As the phenotype distribution of CYP3A4 is similar in Korean and Japanese populations, telaprevir is expected to be less sensitive to ethnic factors between the two ethnicities and to manifest few interethnic differences between Korean and Japanese subjects. Therefore, this study was conducted to 1) investigate the safety, tolerability, and PK characteristics of telaprevir after single and multiple administration in healthy Korean male volunteers in both a fasted and a fed state, and 2) compare these PK characteristics with those of Japanese subjects from a previous study.

\section{Subjects and methods Study population}

Healthy Korean male subjects aged $20-55$ years with a body mass index of $18.5-25.0 \mathrm{~kg} / \mathrm{m}^{2}$ were eligible for this study. Study protocols (ClinicalTrials.gov: NCT01766167) and informed consent forms were reviewed and approved by the Institutional Review Board of Seoul National University Hospital. Written informed consent was obtained from all subjects after providing an adequate explanation of the study. Subjects were evaluated on the basis of medical history, physical examination, vital signs, 12-lead electrocardiography, and clinical laboratory tests. Subjects were excluded if they had any evidence of a current or previous history of cardiac disease or positive results on tests for hepatitis B viral antigen or HCV antibody at the time of examination.

\section{Study design}

This was an open-label, uncontrolled study of telaprevir. The telaprevir used in the study was supplied by Mitsubishi Tanabe Pharma Corporation (Tokyo, Japan) as a $250 \mathrm{mg}$ tablet formulation. In the single ascending dose (SAD) study, 18 participants were assigned to three dose groups $(500,750$, and $1,250 \mathrm{mg})$ and received a single oral dose of telaprevir in the fasted state on Day 1. In the multiple dose study, eight healthy volunteers received $750 \mathrm{mg}$ of telaprevir once in the morning of Day 1, 3 times a day (every $8 \mathrm{~h}$ ) from Day 2 to 5, and once in the morning on Day 6 in the fed state after taking standard breakfast. For the fed state experiments, subjects maintained a fasted state until breakfast before dosing. Otherwise, subjects received regular meals at scheduled times at the study site.

\section{Sample collection and bioanalytical methods}

In the SAD study, $3 \mathrm{~mL}$ blood samples were obtained at 0 (pre-dose), 0.25, 0.5, 0.75, 1, 1.5, 2, 2.5, 3, 4, 5, 6, 8, 10, 12,16 , and $24 \mathrm{~h}$ after drug administration. For the multiple dose study, blood samples were obtained at 0 (pre-dose), $0.25,0.5,0.75,1,1.5,2,2.5,3,4,5,6,8,10,12$, and $16 \mathrm{~h}$ after drug administration on Days 1 and 6; at 0 (pre-dose), 8 , and $16 \mathrm{~h}$ after drug administration on Days 2 and 5; and at 0 (pre-dose) h on Days 3 and 4.

Blood samples were collected in vacuum tubes with EDTA-3K, mixed with inversion 8-10 times, and then cooled on ice immediately. The samples were centrifuged at $1,500 \times \mathrm{g}$ for $10 \mathrm{~min}$ at $4^{\circ} \mathrm{C}$ within $30 \mathrm{~min}$ from the sampling point, and $0.05 \mathrm{~mL}$ of $10 \%$ formic acid was added to $1 \mathrm{~mL}$ of the separated plasma to prevent epimerization of telaprevir.

Plasma concentrations of telaprevir were determined using validated liquid chromatography-mass spectrometry with tandem mass spectrometric detection. The linear range for quantitation of telaprevir in plasma was 2-500 ng/mL, and the lower limit of quantitation was $2.000 \mathrm{ng} / \mathrm{mL}$. Precision and accuracy were evaluated by monitoring quality control samples and standard samples for the calibration curve in the same batch of analytical samples. The telaprevir assays were performed at the Analytical Research Center, Shimura Laboratory, Mitsubishi Chemical Medicine Corporation, Japan.

\section{Safety assessment}

Adverse events (AEs) were identified throughout the study by asking open questions. The following characteristics of all AEs were assessed by the investigator: intensity, time course, outcome, seriousness, and relationship to telaprevir. Vital signs, clinical laboratory tests, physical examinations, and clinical evaluations were conducted to evaluate the safety and tolerability of telaprevir.

\section{PK and statistical analysis}

Individual PK parameters were evaluated using a noncompartmental analysis (NCA) method with WinNonlin ${ }^{\circledR}$ 
(Version 6.4; Certara, Princeton, NJ, USA). The following parameters were calculated or determined: area under the curve (AUC), maximum plasma concentration $\left(\mathrm{C}_{\max }\right)$, concentration at $8 \mathrm{~h}$ after drug administration $\left(\mathrm{C}_{\text {trough }}\right)$, time to reach maximum plasma concentration $\left(\mathrm{t}_{\max }\right)$, apparent clearance $(\mathrm{CL} / \mathrm{F})$, terminal half-life $\left(\mathrm{t}_{1 / 2}\right)$, and apparent volume of distribution $\left(\mathrm{V}_{\mathrm{d}} / \mathrm{F}\right)$. The accumulation ratio of multiple administrations was calculated as the ratio of $\mathrm{C}_{\max }, \mathrm{AUC}_{0-8}$, and $\mathrm{C}_{\text {trough }}$ values on Day 6 to the values on Day 1 in a fed state.

All statistical analyses were performed using SAS 9.2 ${ }^{\circledR}$ (SAS Institute Inc., Cary, NC, USA). Demographic characteristics and $\mathrm{PK}$ parameters were analyzed using descriptive statistics, including mean and percent coefficient of variation (CV\%). Log-transformed $\mathrm{C}_{\max }, \mathrm{AUC}_{0-24}$, and $\mathrm{AUC}_{\text {inf }}$ were analyzed for statistical analysis. Dose proportionality for $\mathrm{C}_{\max }$ and $\mathrm{AUC}_{\text {inf }}$ was examined using power models in the SAD study, and the effect of food on the $\mathrm{C}_{\max }, \mathrm{AUC}_{0-24}$, and $\mathrm{AUC}_{\text {inf }}$ of $750 \mathrm{mg}$ single-dose telaprevir was assessed using an analysis of variance model with a fixed effect for fed or fasted treatment.

\section{Comparison of PK}

In Japan, a randomized, open-label, SAD study of telaprevir was conducted several years earlier (Mitsubishi Tanabe Pharma Corporation, unpublished data, 2013). A single 500,750 , or $1,250 \mathrm{mg}$ dose of telaprevir was administered to healthy Japanese male subjects in the fasted state ( $n=6$ in each dose group), and the subjects in the $750 \mathrm{mg}$ group were administered the same dose again in a fed state. PK samplings were conducted up to $24 \mathrm{~h}$ after the dose was administered. The results of the Japanese PK study were used to compare telaprevir PK characteristics between Korean and Japanese subjects. Log-transformed PK parameters $\left(\mathrm{C}_{\max }\right.$ and $\left.\mathrm{AUC}_{\text {inf }}\right)$ of both ethnicities were analyzed using an analysis of variance model with fixed effects for ethnicity, dose, and dose by ethnicity.

\section{Results}

\section{Subject characteristics}

Demographic characteristics of the 26 subjects enrolled in this study were similar across dose groups, including singledose and multiple-dose studies. Overall, the mean age and body weight $( \pm \mathrm{SD})$ were $27.2 \pm 3.4$ years and $67.4 \pm 7.2 \mathrm{~kg}$, respectively. In the multiple-dose study, two subjects withdrew consent after receiving telaprevir. One subject was withdrawn after the morning dose on Day 4, and the other subject was withdrawn after the first dose on Day 1 . These subjects were included in the safety and tolerability analysis, but excluded from the PK analysis. The demographic characteristics were not significantly different between Korean and Japanese subjects.

\section{Pharmacokinetics}

After oral administration of a single dose of telaprevir in the fasted state, the plasma telaprevir concentration slowly reached $\mathrm{C}_{\max }$ at $3.75-5.00 \mathrm{~h}$ and then declined monoexponentially with a half-life $\left(\mathrm{t}_{1 / 2}\right)$ of 5.37-9.32 h (Table 1 ; Figure 1). In the fasted state, the $\mathrm{C}_{\max }, \mathrm{AUC}_{0-24}$, and $\mathrm{AUC}_{\text {inf }}$

Table I Pharmacokinetic parameters of telaprevir in fasted and fed states after administration of single and multiple doses of telaprevir in healthy Korean subjects

\begin{tabular}{|c|c|c|c|c|c|c|}
\hline \multirow[t]{2}{*}{$\begin{array}{l}\text { Pharmacokinetic } \\
\text { parameters }\end{array}$} & $\begin{array}{l}500 \mathrm{mg} \\
\text { (fasted) }\end{array}$ & $\begin{array}{l}750 \mathrm{mg} \\
\text { (fasted) }\end{array}$ & $\begin{array}{l}\mathrm{I}, 250 \mathrm{mg} \\
\text { (fasted) }\end{array}$ & $\begin{array}{l}750 \text { mg (fed), } \\
\text { Day I }\end{array}$ & $\begin{array}{l}750 \text { mg (fed), } \\
\text { Day } 6\end{array}$ & $\begin{array}{l}\text { Geometric mean } \\
\text { ratio }(90 \% \mathrm{Cl})\end{array}$ \\
\hline & $n=6$ & $n=6$ & $n=6$ & $n=7$ & $n=6$ & ${\text { (fed/fasted })^{a}}^{a}$ \\
\hline $\mathrm{C}_{\max }(\mu \mathrm{g} / \mathrm{mL})$ & $0.247(45.1)$ & $0.514(46.4)$ & $0.448(510.0)$ & $2.316(22.7)$ & $3.132(14.9)$ & $4.918(3.280,7.373)$ \\
\hline$C_{\text {trough }}(\mu g / m L)$ & - & - & - & - & $1.870(\mid 8.8)$ & - \\
\hline$t_{\max }(h)^{b}$ & $3.75(1.00,5.00)$ & $5.00(4.00,5.00)$ & $4.50(1.50,5.00)$ & $6.00(4.00,6.00)$ & $5.00(3.00,5.02)$ & - \\
\hline$A \cup C_{0-8}(\mu \mathrm{g} \cdot \mathrm{h} / \mathrm{mL})$ & I. $10(50.4)$ & $2.40(53.6)$ & $2.2 \mathrm{I}(5 \mathrm{I} .6)$ & $8.82(30.1)$ & $19.32(11.7)$ & - \\
\hline $\mathrm{AUC}_{0-24}(\mu \mathrm{g} \cdot \mathrm{h} / \mathrm{mL})$ & $1.76(43.6)$ & $4.23(51.9)$ & $4.12(60.6)$ & |8.9| (35.3) & $39.90(20.1)$ & $4.81(2.95,7.86)$ \\
\hline $\mathrm{AUC}_{\text {inf }}(\mu \mathrm{g} \cdot \mathrm{h} / \mathrm{mL})$ & I.86 (420.0) & $4.50(49.9)$ & $5.00(60.4)$ & $20.15(37.4)$ & - & $4.73(2.90,7.73)$ \\
\hline $\mathrm{CL} / \mathrm{F}(\mathrm{L} / \mathrm{h})$ & $329.77(550.0)$ & $217.81(62.8)$ & $362.29(70.2)$ & $42.89(41.9)$ & $39.25(11.4)$ & - \\
\hline$V_{d} / F$ & $2,691.57(65.5)$ & I,778.46 (73.I) & $4,617.70(78.4)$ & $275.56(32.9)$ & $565.70(40.0)$ & \\
\hline $\mathrm{t}_{1 / 2}(\mathrm{~h})$ & $5.64(36.5)$ & $5.37(23.2)$ & $9.32(40.6)$ & $4.67(25.8)$ & $10.34(49.1)$ & - \\
\hline Accumulation ratio of $\mathrm{C}_{\max }$ & - & - & - & - & I.46I (2I.I) & - \\
\hline Accumulation ratio of $\mathrm{AUC}_{0-8}$ & - & - & - & - & $2.413(24.0)$ & - \\
\hline Accumulation ratio of $C_{\text {trough }}$ & - & - & - & - & $1.540(37.9)$ & - \\
\hline
\end{tabular}

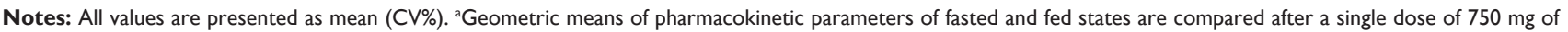
telaprevir. ${ }^{b} t_{\max }$ is presented as the median (minimum, maximum).

Abbreviations: $A \cup C_{0-t}$, area under the concentration-time curve until time point of $t ; A \cup C_{\text {inf }}$ area under the concentration-time curve to infinity; $C L / F$, apparent clearance; $\mathrm{C}_{\text {max }}$, peak plasma concentration; $\mathrm{C}_{\text {trough }}$, minimum plasma concentration; $\mathrm{CV} \%$, percent coefficient of variation; $t_{1 / 2}$, terminal elimination half-life; $t_{\text {max }}$, time to peak plasma concentration; $\mathrm{V}_{\mathrm{d}} / \mathrm{F}$, apparent volume of distribution. 

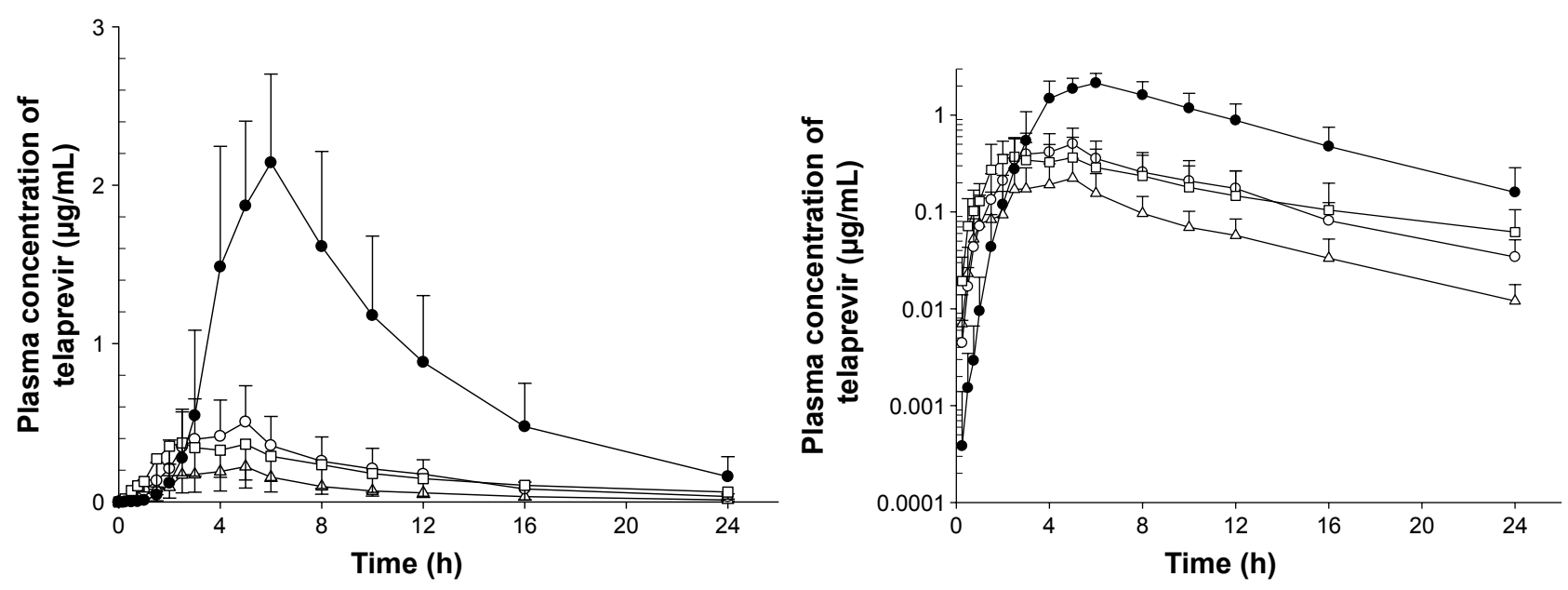

$\triangle \backsim 500 \mathrm{mg}$, fasted state $(\mathrm{n}=6)-0-750 \mathrm{mg}$, fasted state $(\mathrm{n}=6)-\square-1,250 \mathrm{mg}$, fasted state $(\mathrm{n}=6)-\longrightarrow$

Figure I Mean plasma concentration-time plot after a single oral dose of telaprevir 500, 750, or I,250 mg in fasted and fed states (left, linear scale; right, semi-logarithmic scale).

of telaprevir tended to increase with increasing dose. When log-transformed $\mathrm{C}_{\max }, \mathrm{AUC}_{0-24}$, and $\mathrm{AUC}_{\text {inf }}$ were assessed with the power model, dose proportionality was observed with a wide CI range.

Repeated telaprevir administration every $8 \mathrm{~h}$ for 6 days under the fed condition resulted in a cumulative increase in plasma telaprevir concentration (Table 1; Figure 2). The accumulation ratios of $\mathrm{C}_{\text {max }}, \mathrm{AUC}_{0-8}$, and $\mathrm{C}_{\text {trough }}$ were 1.461, 2.413, and 1.540, respectively, after 6-day multiple administrations.

Following the administration of $750 \mathrm{mg}$ telaprevir with food, the $\mathrm{C}_{\max }, \mathrm{AUC}_{0-24}$, and $\mathrm{AUC}_{\text {inf }}$ of telaprevir increased by $\sim 4.73$-fold compared to values in the fasted condition (Table 1). These results suggest a significant effect of food on telaprevir exposure. Food did not affect the $t_{1 / 2}$ in the $750 \mathrm{mg}$ dose group, but the $\mathrm{t}_{\text {max }}$ was delayed to $6 \mathrm{~h}$ after drug administration compared to $5 \mathrm{~h}$ in the fasted group.

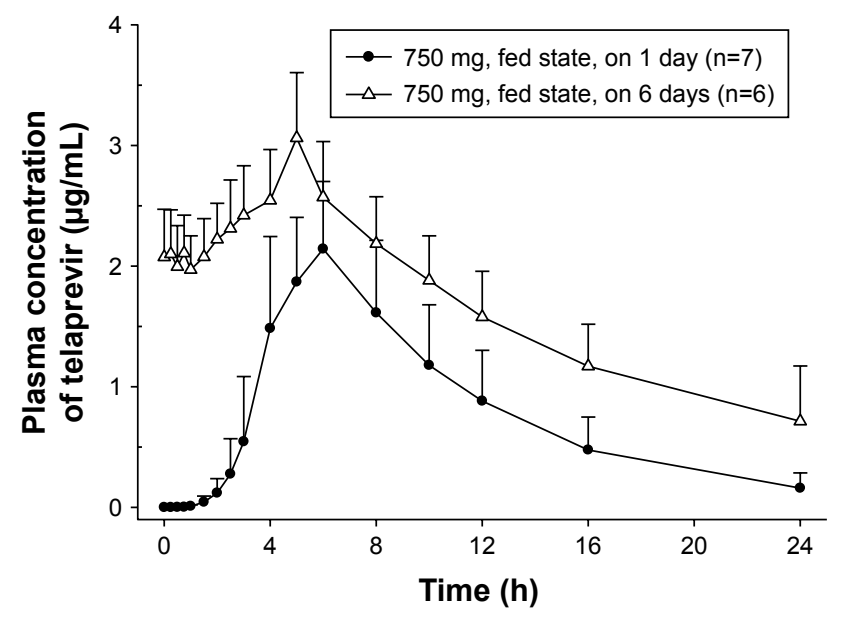

Figure 2 Mean plasma concentration-time plot after a single dose ( I day) and at steady state after multiple doses (6 days) of telaprevir $750 \mathrm{mg}$ in a fed state.
When the PK profiles of telaprevir in Korean subjects were compared with those in Japanese subjects (Table 2), the extent of telaprevir exposure was $20 \%-30 \%$ higher in the Korean subjects. However, $90 \%$ CIs of geometric mean ratios of $\mathrm{C}_{\text {max }}$ and $\mathrm{AUC}_{\text {inf }}$ in Korean versus Japanese subjects included the value of unity $(1.260[0.925,1.717]$ and 1.337 $[0.973,1.838]$ as point estimate $[90 \% \mathrm{CI}]$, respectively) and high variability (CV\% of $46.4 \%$ and $49.9 \%$, respectively). Distributions of dose-normalized $\mathrm{C}_{\max }$ and $\mathrm{AUC}_{\text {inf }}$ were also similar between Korean and Japanese subjects (Figure 3). Thus, the difference in PK profiles between the two ethnicities was not clinically significant.

\section{Safety and tolerability}

A single telaprevir dose of up to $1,250 \mathrm{mg}$ and multiple doses of $750 \mathrm{mg}$ for 6 days were generally safe and well tolerated in healthy subjects. A total of nine AEs occurred, and they were considered to be related to telaprevir in 7 out of 18 Korean subjects in the SAD study. Asthenia (two cases) and diarrhea (two cases) were the most frequently reported AEs. In the multiple-dose study, 12 AEs were reported in five out of eight subjects, and abdominal distension was the most common AE. All these AEs were considered mild, and subjects recovered without sequelae. There were no clinically important changes relative to the baseline laboratory test values or vital signs, or electrocardiography and physical examination findings.

\section{Discussion}

The objective of this study was to investigate the PK and safety profile of telaprevir, including the effect of food on telaprevir exposure and the extent of accumulation after 
Table 2 Pharmacokinetic parameters of telaprevir in fasted and fed states after administration of single dose of telaprevir in healthy Japanese subjects

\begin{tabular}{|c|c|c|c|c|}
\hline \multirow{2}{*}{$\begin{array}{l}\text { Pharmacokinetic } \\
\text { parameters }\end{array}$} & $500 \mathrm{mg}$ (fasted) & $750 \mathrm{mg}$ (fasted) & $\mathrm{I}, 250 \mathrm{mg}$ (fasted) & 750 mg (fed) \\
\hline & $n=6$ & $n=6$ & $n=6$ & $n=6$ \\
\hline $\mathrm{C}_{\max }(\mu g / \mathrm{mL})$ & $0.183(35.7)$ & $0.310(53.0)$ & $0.494(55.6)$ & $2.325(49.7)$ \\
\hline $\mathrm{t}_{\max }(\mathrm{h})^{\mathrm{a}}$ & $3.50(2.50,6.00)$ & $4.00(2.00,6.00)$ & $4.00(2.50,6.00)$ & $4.00(4.00,6.00)$ \\
\hline $\mathrm{AUC}_{0-8}(\mu \mathrm{g} \cdot \mathrm{h} / \mathrm{mL})$ & $0.86(39.6)$ & $1.58(65.3)$ & 2.31 (47.7) & $9.27(49.7)$ \\
\hline $\mathrm{AUC}_{0-24}(\mu \mathrm{g} \cdot \mathrm{h} / \mathrm{mL})$ & I.24 (39.5) & $2.80(63.4)$ & $3.73(57.3)$ & $14.03(53.9)$ \\
\hline$A \cup C_{\text {inf }}(\mu \mathrm{g} \cdot \mathrm{h} / \mathrm{mL})$ & $1.30(39.8)$ & $3.38(62.3)$ & $3.99(56.4)$ & I $4.43(55.1)$ \\
\hline $\mathrm{CL} / \mathrm{F}(\mathrm{L} / \mathrm{h})$ & $478.37(63.1)$ & $312.53(61.6)$ & $40 I .31$ (49.I) & $65.09(49.4)$ \\
\hline$V_{d} / F(L)$ & 3,302.99 (7I.4) & $3,152.33(53.5)$ & $4,309.74(134.4)$ & $360.25(42.8)$ \\
\hline $\mathrm{t}_{1 / 2}(\mathrm{~h})$ & $4.77(37.1)$ & $7.41(35.4)$ & $6.38(88.3)$ & $3.97(13.4)$ \\
\hline
\end{tabular}

Notes: All values are presented as mean $(\mathrm{CV} \%) .{ }^{a} \mathrm{t}_{\max }$ is presented as the median (minimum, maximum).

Abbreviations: $\mathrm{AUC}_{0-\mathrm{t}}$, area under the concentration-time curve until time point of $\mathrm{t} ; \mathrm{AUC}$, area under the concentration-time curve to infinity; $\mathrm{CL} / \mathrm{F}$, apparent clearance; $\mathrm{C}_{\text {max }}$, peak plasma concentration; $\mathrm{CV} \%$, percent coefficient of variation; $\mathrm{t}_{\mathrm{l} / 2}$, terminal elimination half-life; $\mathrm{t}_{\max }$, time to peak plasma concentration; $\mathrm{V}_{\mathrm{d}} / \mathrm{F}$, apparent volume of distribution.

multiple doses of telaprevir in healthy subjects. NCA revealed a CV\% of exposure that ranged from $35 \%$ to $63 \%$ in both the fasted and fed states, implying that telaprevir PK varies widely between subjects. This variability was consistent with the results of previous studies where $\mathrm{AUC}_{0-8}, \mathrm{C}_{\max }$, and $\mathrm{C}_{\min }$ ranged from $19 \%$ to $48 \% .{ }^{8} \mathrm{PK}$ analysis revealed that the dose proportionality of telaprevir was unclear after SADs from 500 to $1,250 \mathrm{mg}$, likely because of the large PK variability.

The $\mathrm{CL} / \mathrm{F}$ at the steady state after multiple doses was comparable to that of the first dose, whereas the half-life and $\mathrm{V}_{\mathrm{d}} / \mathrm{F}$ were more than doubled. Considering that telaprevir is extensively metabolized by the hepatic CYP3A enzyme and transported by the P-glycoprotein (P-gp) transporter, timedependent inhibition of hepatic CYP3A4 might have caused the increased half-life and decreased drug elimination after multiple administrations. ${ }^{9-11}$ However, little change of $\mathrm{CL} / \mathrm{F}$ and increased $\mathrm{V}_{\mathrm{d}} / \mathrm{F}$ were not consistent with a previous report, where clearance was reduced at steady state. ${ }^{15}$ Change of $\mathrm{F}$ after multiple administrations has not been investigated in the former studies, but if any, it might be increased because of time-dependent inhibition and saturation of intestinal CYP3A4 and P-gp transporter. Change of F might have affected $\mathrm{CL} / \mathrm{F}$ and $\mathrm{V}_{\mathrm{d}} / \mathrm{F}$, but increased $\mathrm{V}_{\mathrm{d}} / \mathrm{F}$ could not be explained with these factors or other findings of this study.

In this study, highly variable PK characteristics were observed when $\mathrm{CV} \%$ values were calculated. We also observed delayed telaprevir absorption after oral administration in the fasted state, with a median $\mathrm{t}_{\max }$ of $3.75-5.00 \mathrm{~h}$. In a previous study, telaprevir absorption was characterized by an initial slow phase followed by a second rapid phase, with an average lag time of $0.21 \mathrm{~h} .{ }^{12}$ These features seem to be partly due to the lipophilicity of telaprevir, which results in a long intestinal transit time and high variability in the absorption process, thereby affecting $\mathrm{C}_{\max }$ and $\mathrm{t}_{\max }{ }^{4}$

Assessment of the effect of food on telaprevir exposure after administration of the $750 \mathrm{mg}$ dose revealed that food intake significantly increased telaprevir exposure by a maximum of 5.73-fold, and the median value of $t_{\max }$ increased up to $6 \mathrm{~h}$ compared to exposure under the fasted condition. This result is consistent with the findings of another study where
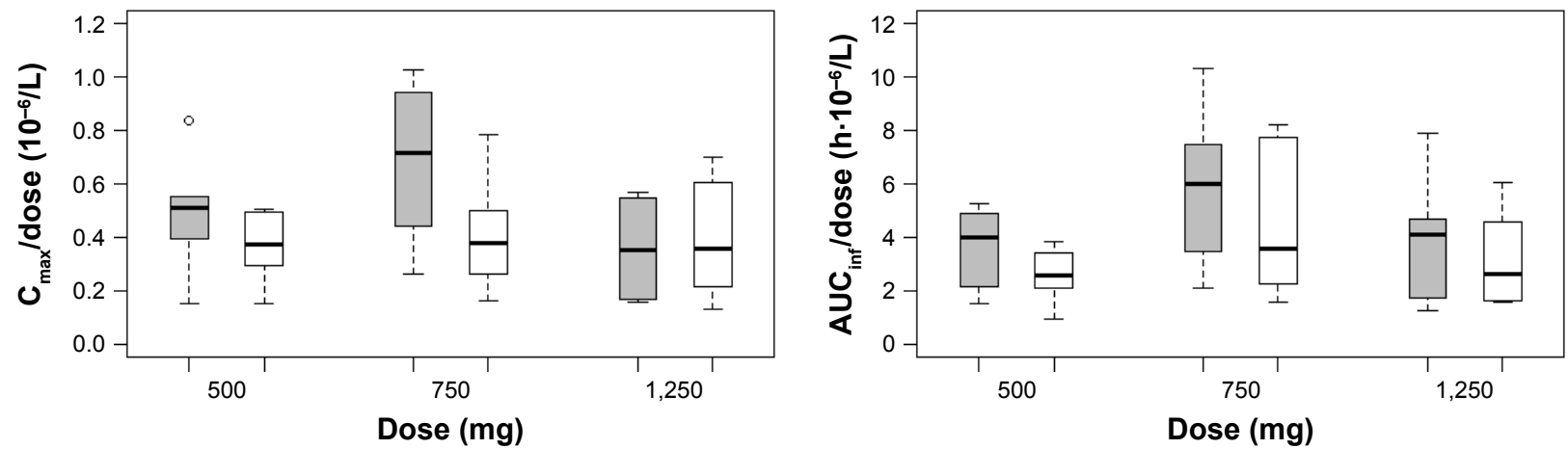

$\square$ Korean $\square$ Japanese

Figure 3 Box plots of dose-normalized $\mathrm{C}_{\max }$ (left) and $\mathrm{AUC}_{\text {inf }}$ (right) after a single oral dose of 500, 750, or I,250 mg of telaprevir in Korean and Japanese subjects. 
food intake enhanced telaprevir exposure by 3- to 4-fold. ${ }^{5}$ The bioavailability of telaprevir during the absorption and metabolism phases is determined by several factors, including the aforementioned transporters and metabolic enzymes, and dissolution, ionization, and gastric emptying time. It can be suggested that intake of standard meal increases the solubility of telaprevir which is lipid soluble, and food intake increases the transit time and duration of absorption of telaprevir in the small intestine, thereby resulting in increased $\mathrm{T}_{\max }$ and total intestinal absorption of telaprevir. Food intake mainly delayed and prolonged absorption phase of telaprevir, but did not significantly affect elimination of telaprevir, considering that $\mathrm{t}_{1 / 2}$ of telaprevir after single dose was similar in the fasted group and the fed group. Meanwhile, it is less likely that absorption of telaprevir was affected by $\mathrm{pH}$ change after food intake, because dissolution of telaprevir is independent of $\mathrm{pH}$. The variability of bioavailability is also affected by several factors, and the types of food or total food intake itself may influence the bioavailability of telaprevir, although the absolute bioavailability of telaprevir has not been determined in humans. ${ }^{8,13}$

The lipophilic characteristics of telaprevir may influence the distribution phase by allowing it to penetrate tissues beyond the systemic circulation, resulting in a large apparent volume of distribution $\left(\mathrm{V}_{\mathrm{d}} / \mathrm{F}\right)$ with high intraindividual variability. ${ }^{5}$ In Korean subjects, $\mathrm{CV} \%$ of $\mathrm{V}_{\mathrm{d}} / \mathrm{F}$ was $78.7 \%$, which was consistent with the results of a pooled population PK analysis conducted in previous Phase 2 and 3 studies where intersubject variability was estimated as $72.2 \% .^{8}$ The expression of the P-gp transporter and the CYP3A4 are also potential sources of high variability of telaprevir absorption and metabolism. ${ }^{10,14}$ When telaprevir was administered under fed conditions in this study, interindividual variabilities of $\mathrm{C}_{\text {max }}, \mathrm{AUC}_{0-8}$, and $\mathrm{AUC}_{0-24}$ were smaller than those under fasted conditions. The high variability of $\mathrm{PK}$ parameters under fasted conditions may be partly due to the highly variable bioavailability of telaprevir. In addition, the variability of PK parameters might decrease after food intake because of increased bioavailability and decreased variability due to diet.

Clinically, telaprevir is prescribed with other drugs such as antiviral agents to avoid drug resistance and enhance viral eradication or immunosuppressants in posttransplantation treatment. Thus, drug interaction should be assessed before prescription and monitored during the treatment period. Regarding peg-interferon and ribavirin which are used in combination with telaprevir, the $\mathrm{AUC}$ and $\mathrm{C}_{\max }$ of telaprevir were increased by about $30 \%-40 \%$ after coadministration with peg-interferon, while ribavirin did not affect telaprevir exposure and telaprevir did not change the exposure of either peg-interferon or ribavirin in a previous study. ${ }^{5}$ For other drugs, a significant increase of AUC and $\mathrm{C}_{\text {max }}$ (more than 5-fold) of tacrolimus, midazolam, or atorvastatin was observed after coadministration with telaprevir in other studies. Some drug interactions with telaprevir can be explained by telaprevir's inhibitory effect on CYP3A4 metabolic pathway (eg, tacrolimus, midazolam, and so on) or on organic anion-transporting polypeptide transporter (eg, atorvastatin); however, the mechanisms of most interactions still remain to be studied. $5,9,15,16$

When the PK exposure parameters $\left(\mathrm{C}_{\max }, \mathrm{AUC}_{0-24}\right.$, and $\mathrm{AUC}_{\text {inf }}$ ) calculated using NCA were compared between Korean and Japanese subjects, we found small differences in both fasting and fed states. However, these differences were considered clinically insignificant. Because of the wide therapeutic range and large individual variability of PK-pharmacodynamic characteristics of telaprevir, the difference in exposures between Korean and Japanese subjects is trivial from a clinical perspective. ${ }^{17}$ When the individual dose-normalized $\mathrm{C}_{\max }$ and $\mathrm{AUC}_{\text {inf }}$ were plotted, their distributions were similar between Korean and Japanese subjects (Figure 3). Moreover, the $90 \%$ CI of the geometric mean ratio of each exposure parameter included the value of unity, suggesting that the difference between the two ethnic groups was statistically insignificant. Additionally, while telaprevir is mainly metabolized by hepatic CYP3A4, ethnic-based genetic differences in the effect of CYP3A4 on the PK of telaprevir may be minimal because allele frequencies of CYP3A4 are similar between the Korean and Japanese populations. $^{6}$

This study has some limitations. Although subject demographic characteristics were homogeneous and well distributed throughout the dose groups, the sample size, with only six subjects in each fasted group and eight subjects in the fed group, was small for investigating the PK parameters in the presence of large variability. Also, sex differences in PK characteristics could not be analyzed because only male subjects were included in this study. Considering the characteristics of absorption, distribution, and metabolism of telaprevir, a study with a larger sample size is warranted for the evaluation of dose proportionality and ethnic differences.

In conclusion, when single doses of telaprevir ranging from 500 to $1,250 \mathrm{mg}$ were administered to healthy Korean subjects, dose proportionality was unclear because of large variability and telaprevir exposure was increased after food intake. Telaprevir was well tolerated up to $1,250 \mathrm{mg}$ as a 
single dose in the fasting state and as $750 \mathrm{mg}$ multiple doses in the fed state. Moreover, the PK characteristics were similar in healthy Korean and Japanese male subjects.

\section{Acknowledgments}

We would like to appreciate all the support of the staff at the Clinical Trial Center, Seoul National University Hospital during the conduct of this study. This work was supported by Mitsubishi Tanabe Pharma Corporation, Tokyo, Japan, who sponsored the study.

\section{Disclosure}

KM and YO are employees of Mitsubishi Tanabe Pharma Corporation, Tokyo, Japan. The authors report no other conflicts of interest in this work.

\section{References}

1. Cooke GS, Lemoine M, Thursz M, et al. Viral hepatitis and the global burden of disease: a need to regroup. J Viral Hepat. 2013;20(9):600-601.

2. Messina JP, Humphreys I, Flaxman A, et al. Global distribution and prevalence of hepatitis C virus genotypes. Hepatology. 2015;61(1):77-87.

3. Forestier N, Reesink HW, Weegink CJ, et al. Antiviral activity of telaprevir (VX-950) and peginterferon alfa-2a in patients with hepatitis C. Hepatology. 2007;46(3):640-648.

4. Fowell AJ, Nash KL. Telaprevir: a new hope in the treatment of chronic hepatitis C? Adv Ther. 2010;27(8):512-522.

5. Garg V, Kauffman RS, Beaumont M, van Heeswijk RP. Telaprevir: pharmacokinetics and drug interactions. Antivir Ther. 2012;17(7): 1211-1221.

6. Lee JS, Cheong HS, Kim LH, et al. Screening of genetic polymorphisms of CYP3A4 and CYP3A5 genes. Korean J Physiol Pharmacol. 2013;17(6):479-484.
7. National Institute of Food and Drug Safety Evaluation. Guideline for Bridging Study. Osong, Republic of Korea: National Institute of Food and Drug Safety Evaluation, Drug Evaluation Department; 2015.

8. Seo SK, Robertson SM. Clinical Pharmacology and Biopharmaceutics Review(s). Application Number 201917Orig1s000. Silver Spring, MD: Center for Drug Evaluation and Research; 2011.

9. Incivek ${ }^{\circledR}$ (telaprevir) [package insert]. Cambridge, MA: Vertex Pharmaceuticals Incorporated; 2011.

10. Garg V, Chandorkar G, Yang Y, et al. The effect of CYP3A inhibitors and inducers on the pharmacokinetics of telaprevir in healthy volunteers. Br J Clin Pharmacol. 2013;75(2):431-439.

11. Weiss J, Becker JP, Haefeli WE. Telaprevir is a substrate and moderate inhibitor of P-glycoprotein, a strong inductor of ABCG2, but not an activator of PXR in vitro. Int J Antimicrob Agents. 2014;43(2):184-188.

12. Lawitz E, Rodriguez-Torres M, Muir AJ, et al. Antiviral effects and safety of telaprevir, peginterferon alfa-2a, and ribavirin for 28 days in hepatitis C patients. J Hepatol. 2008;49(2):163-169.

13. Van Heeswijk R, Boogaerts G, De Paepe E, et al. The effect of different types of food on the bioavailability of the investigational $\mathrm{HCV}$ protease inhibitor telaprevir [abstract 19]. Paper presented at: 6th International Workshop on Clinical Pharmacology of Hepatitis Therapy; Cambridge, MA; 2011.

14. Fudin J, Fontenelle DV, Fudin HR, Carlyn C, Hinden DA, Ashley CC. Potential P-glycoprotein pharmacokinetic interaction of telaprevir with morphine or methadone. J Pain Palliat Care Pharmacother. 2013; 27(3):261-267.

15. Kiang TK, Wilby KJ, Ensom MH. Telaprevir: clinical pharmacokinetics, pharmacodynamics, and drug-drug interactions. Clin Pharmacokinet. 2013;52(7):487-510.

16. Wilby KJ, Greanya ED, Ford JA, Yoshida EM, Partovi N. A review of drug interactions with boceprevir and telaprevir: implications for HIV and transplant patients. Ann Hepatol. 2012;11(2):179-185.

17. Reesink HW, Zeuzem S, Weegink CJ, et al. Rapid decline of viral RNA in hepatitis C patients treated with VX-950: a phase Ib, placebocontrolled, randomized study. Gastroenterology. 2006;131(4):997-1002.

\section{Publish your work in this journal}

Drug Design, Development and Therapy is an international, peerreviewed open-access journal that spans the spectrum of drug design and development through to clinical applications. Clinical outcomes, patient safety, and programs for the development and effective, safe, and sustained use of medicines are the features of the journal, which

\section{Dovepress}

has also been accepted for indexing on PubMed Central. The manuscript management system is completely online and includes a very quick and fair peer-review system, which is all easy to use. Visit http://www.dovepress.com/testimonials.php to read real quotes from published authors. 